\title{
EFFECTS OF CORTICOTROPIN ON BODY WATER AND \\ ELECTROLYTES IN PATIENTS WITH \\ RHEUMATIC DISEASE ${ }^{1}$
}

\author{
BY NORMAN DEANE, MORRIS ZIFF, AND JOSEPH J. BUNIM 2 \\ (From the Departments of Physiology and Medicine, New York University College of Medicine, \\ and the Study Growp on Rheumatic Diseases, New York University-Bellewie \\ Medical Center)
}

(Submitted for publication January 24, 1953; accepted May 22, 1953)

The therapeutic response to pituitary adrenocorticotropic hormone is often accompanied by profound changes in water, solid, and electrolyte distribution. Metabolic balance studies in patients receiving corticotropin (1) have demonstrated marked initial retention of sodium and chloride and subsequently increased excretion of these ions while potassium balance remained negative. Bartter and his co-workers (2), studying patients with panhypopituitarism who were receiving corticotropin, observed that retention of sodium was greater than that of chloride, and concluded that sodium entered cells when corticotropin was given, and left the cells during the recovery periods. There was a large but transient loss of potassium within 24 hours after the beginning of treatment and a corresponding retention of potassium at the beginning of the postcorticotropin period. A transient increase in the inulin space in patients treated with corticotropin and cortisone, and maintained on rigid salt restriction, has been reported by Levitt and Bader (3). Since the patients studied by these authors were on a markedly restricted salt intake and remained in salt balance, without gain in weight, it was concluded that the observed increase in the extracellular fluid volume was due to a shift of salt and water from the intracellular compartment. Recently, Ziff, Simson, and Bunim (4) reported variation in the manner of water re-

1 This study was supported by grants from the Atomic Energy Commission (AEC Contract AT (30-1)-1025) and the Commonwealth Fund to the Department of Physiology and by grants from the Masonic Foundation for Medical Research and Human Welfare and the Squibb Institute for Medical Research to the Study Group on Rheumatic Diseases.

2 Present address: National Institute of Arthritis and Metabolic Diseases, National Institutes of Health, Bethesda, Maryland. tention by different individuals during corticotropin administration. This was predominantly intracellular in some cases and extracellular in others, as determined from the simultaneous measurement of antipyrine and bromide spaces. The present study is designed to quantitate further some aspects of the changes in body water and electrolyte metabolism which may be encountered during this induced state of adrenalcortical hyperfunction.

\section{METHODS}

Extracellular fluid volume was measured by the calibrated infusion technique (5) using sucrose. Total body water was determined by the antipyrine ${ }^{3}$ method (6). Total exchangeable sodium and potassium (7) and chloride (8) were measured by dilution techniques employing radiosodium $\left(\mathrm{Na}^{\mathrm{*}}\right)$, radiopotassium $\left(\mathrm{K}^{\mathrm{s}}\right)$ and bromide. Extracellular and non-extracellular * electrolyte and total body solids were calculated as described in previous papers. Extracellular sodium and potassium were calculated as the products of extra-cellular fluid volume and plasma concentration. Corrections for plasma water $(W=0.92)$ and the Donnan factor $(K=1.02)$ have been made in the calculations of extracellular chloride.

When bromide studies (9) were repeated at weekly intervals in the measurement of body chloride, significant concentrations of bromide were present in control plasmas. Correction for the fall in the control level of bromide during the 24-hour equilibration period, the magnitude of which varied from two to eight per cent, was made as described by Ziff, Simson, and Bunim (4).

The patients were given a standard hospital low salt

3 Antipyrine was supplied in sterile ampules by Eli Lilly \& Co.

- By non-extracellular electrolyte, we mean the part of total body electrolyte which is not contained in the extracellular fluid volume as measured by the sucrose volume of distribution. Thus, non-extracellular electrolyte includes all intracellular electrolytes as well as the portion of total exchangeable electrolyte which may not literally be within the limits of cell membranes (bone sodium, for example). 
diet which, by dietetic analysis, had an average daily composition of carbohydrate $230 \mathrm{Gm}$., protein $55 \mathrm{Gm}$., fat $55 \mathrm{Gm}$., potassium $2.8 \mathrm{Gm}$., sodium $0.40 \mathrm{Gm}$. and chloride $0.66 \mathrm{Gm}$. This diet was supplemented by $4 \mathrm{Gm}$. of sodium chloride which was presented to the patient in a weighed salt shaker. All patients were on the diet and salt supplement for at least five days prior to the control study. The patients consumed the full diet and salt supplement throughout the period of observation. Corticotropin was administered intramuscularly every six hours in the dosages indicated in the tables. ${ }^{5}$

The patients were as follows:

\begin{tabular}{lcll}
\hline \hline Initials & Age & Sex & \multicolumn{1}{c}{ Diagnosis } \\
\hline T. T. & 15 & Male & Rheumatoid Spondylitis \\
R. F. & 14 & Male & Rheumatic Fever \\
H. C. & 17 & Female & Rheumatic Fever \\
W. C. & 42 & Female & Rheumatoid Arthritis \\
\hline
\end{tabular}

Clinical summaries are appended.

\section{RESULTS}

The results (Tables I-IV) in the four patients studied are summarized as follows. Three of the patients (T. T., R. F., W. C.) gained weight (range 1.9 to $8.5 \mathrm{Kg}$.) while one (H. C.) had lost $4 \mathrm{Kg}$. at the end of 22 days of corticotropin therapy. The values for total body water and total body solids indicate the nature of these weight changes. Of the three patients who gained weight, T. T. and R. F. (Tables I and II) present a similar pattern. The progressive increase in total body water reflects a continuing positive water balance which is most marked during the first week of treatment. This fluid is retained as

- Corticotropin (pork ACTH) was supplied by Armour \& Co. Dosages are expressed in milligrams equivalent to Armour standard LA-1-A. cell water, as the values for extracellular and intracellular water indicate. As a result of initial decrease in extracellular water, however, cellular hydration is increased by an amount greater than the volume of water retained. Thus the positive water balance is associated with a shift of extracellular water into the cells. Restoration of extracellular fluid volume was complete in T. T. (Table I) after 43 days of treatment and partial in R. F. (Table II) after 34 days of treatment. Both patients displayed a marked decrease of total body solids during the first five-day period, and this value continued to decrease as shown by tests performed on the thirteenth day in R. F. and the nineteenth day in T. T. Side effects of corticotropin administration such as moon face and acne were prominent when the final measurements were made in these patients, at which time the mass of total body solid had returned to values greater than those measured in the control study. This requires the assumption of a positive solid balance with deposition of either body fat or protein late in the course of corticotropin treatment.

In W. C. (Table III), the gain in weight was related to a different sequence of events. No significant change in total body water occurred during twelve days of treatment although a transient shift of 2.4 liters of cell water to the extracellular fluid was observed on the fifth day. The increase in body weight during this period was due to an increase in body solid. After two weeks, the patient began to gain weight rapidly, concurrently developing signs of marked extracellular fluid volume expansion, that is, peripheral edema, ascites, pulmonary congestion, and elevated venous pres-

TABLE I

Rheumatoid spondylitis

T. T., 15 years, ACTH dosage $=100 \mathrm{mg} . / \mathrm{day}$

\begin{tabular}{|c|c|c|c|c|}
\hline Day of ACTH administration & Control & 5 & 19 & 43 \\
\hline $\begin{array}{l}\text { Weight (Kg.) } \\
\text { Total body water (liters) } \\
\text { Extracellular water (liters) } \\
\text { Intracellular water (liters) } \\
\text { Total body solids (Kg.) } \\
\text { Total body sodium (mEq.) } \\
\text { Plasma sodium concentration (mEq./L.) } \\
\text { Extracellular sodium (mEq.) } \\
\text { Non-extracellular sodium (mEq.) } \\
\text { Total body chloride (mEq.) } \\
\text { Plasma chloride concentration (mEq./L.) } \\
\text { Extracellular chloride (mEq.) } \\
\text { Non-extracellular chloride (mEq.) }\end{array}$ & $\begin{array}{r}28.3 \\
16.1 \\
8.5 \\
7.6 \\
12.2 \\
1,450 . \\
140 . \\
1,190 . \\
260 . \\
1,210 . \\
106 . \\
1,110 . \\
100 .\end{array}$ & $\begin{array}{r}30.0 \\
19.3 \\
7.2 \\
12.1 \\
10.7 \\
1,480 . \\
139 \\
1,000 \\
480 . \\
1,160 . \\
105 \\
840 . \\
320\end{array}$ & $\begin{array}{c}31.3 \\
21.9 \\
7.5 \\
14.4 \\
9.4 \\
1,520 . \\
136 . \\
1,020 . \\
500 .\end{array}$ & $\begin{array}{r}36.8 \\
23.2 \\
8.5 \\
14.7 \\
13.6 \\
1,790 . \\
144 . \\
1,220 . \\
570 . \\
1,480 . \\
108 . \\
1,020 \\
460\end{array}$ \\
\hline
\end{tabular}


TABLE II

Acute rheumatic fever

R. F., 14 years, ACTH dosage $=100 \mathrm{mg} . /$ day

\begin{tabular}{|c|c|c|c|c|}
\hline Day of ACTH administration & Control & 5 & 13 & 34 \\
\hline $\begin{array}{l}\text { Weight (Kg.) } \\
\text { Total body water (liters) } \\
\text { Extracellular water (liters) } \\
\text { Intracellular water (liters) } \\
\text { Total body solids (Kg.) } \\
\text { Total body sodium (mEq.) } \\
\text { Plasma sodium concentration (mEq./L.) } \\
\text { Extracellular sodium (mEq.) } \\
\text { Non-extracellular sodium (mEq.) }\end{array}$ & $\begin{array}{r}53.9 \\
34.7 \\
13.3 \\
21.4 \\
19.2 \\
2,200 . \\
134 . \\
1,780 . \\
420 .\end{array}$ & $\begin{array}{c}56.0 \\
38.2 \\
12.4 \\
25.8 \\
17.8 \\
\\
133 .\end{array}$ & $\begin{array}{r}55.5 \\
39.5 \\
10.4 \\
29.1 \\
16.0 \\
2,340 . \\
135 \\
1,410 \\
930\end{array}$ & $\begin{array}{l}60.5 \\
40.5 \\
11.5 \\
29.0 \\
20.0 \\
\\
140 .\end{array}$ \\
\hline
\end{tabular}

sure, which did not respond to salt restriction, diuretics or digitalis therapy. After the study on the nineteenth day, corticotropin was discontinued. The increase of 7.5 liters in extracellular fluid from day 12 to 19 was effected by a positive water balance of 4.3 liters and a shift to the extracellular fluid of 3.2 liters of cell water. Total body solids continued to increase during this interval.

Although H. C. (Table IV) lost weight, the alterations induced by corticotropin in this patient are of a similar pattern to those initially noted in W. C. Total body water decreased progressively during treatment, indicating a negative water balance. This water loss was met exclusively from the intracellular water since the data show that extracellular fluid volume did not fall below the control value at any time during treatment. A transient shift of cell water to the extracellular fluid was noted in this patient (H. C., Table IV, Day 15). In contrast to T. T. and R. F. who had a marked decrease in body solids during the initial period on corticotropin, H. C. and W. C. registered increases in total solids indicating positive fat or protein balance.

Serial measurements of total body sodium and its distribution were performed in three patients, T. T., R. F. and H. C. (Tables I, II, and IV). Corticotropin induced sodium retention with an increase in total body sodium in each patient. The sodium distribution measurements indicate that all or the greater part of this retained sodium became part of the non-extracellular electrolyte. A comparison of the control value for non-extracellular sodium with the first measurement after institution of corticotropin therapy showed an increase of 180 per cent in T. T., 220 per cent in R. F. and 130 per cent in $H$. C.

Changes in the amount and distribution of body chloride were observed in three patients. Two patients, H. C. and T. T. (Tables I, IV) showed a pattern for chloride similar to that described for sodium. There was retention of chloride, and increase in non-extracellular chloride after 15 and 43 days of treatment, respectively. In $W$. C., the

TABLE III

Rheumatoid arthritis

W. C., 42 years, ACTH dosage $=100 \mathrm{mg} . / \mathrm{day}$

\begin{tabular}{lcccc}
\hline \multicolumn{1}{c}{ Day of ACTH administration } & Control & 5 & 12 & 19 \\
\hline Weight (Kg.) & 50.2 & 50.2 & 53.4 & 58.6 \\
Total body water (liters) & 29.9 & 29.5 & 29.0 & 33.3 \\
Extracellular water (liters) & 10.4 & 12.8 & 10.7 & 18.2 \\
Intracellular water (liters) & 19.5 & 16.7 & 18.3 & 15.1 \\
Total body solids (Kg.) & 20.3 & 20.7 & 24.4 & 25.3 \\
Total body chloride (mEq.) & $1,730$. & $1,870$. & $1,910$. & $1,530$. \\
Plasma chloride concentration (mEq./L.) & 108. & 109. & 104. & 101. \\
Extracellular chloride (mEg.) & $1,250$. & $1,550$. & $1,240$. & $2,070$. \\
Non-extracellular chloride (mEq.) & 480. & 320. & 670. & 460. \\
\hline
\end{tabular}

* Determined by $\mathrm{D}_{2} \mathrm{O}$ Method. Analyses were carried out by Mr. Irving Sucher of Columbia University on the mass spectrometer. Blood samples were collected till 12 hours after injection for determination of equilibrium concentration of $\mathrm{D}_{2} \mathrm{O}$. 
TABLE IV

Rheumatic fower. and shemmatic heart disease

H. C., 17 years, ACTH dosage $=100 \mathrm{mg} . /$ day

\begin{tabular}{|c|c|c|c|c|}
\hline Day of ACTH administration & Control & 6 & 15 & 27 \\
\hline $\begin{array}{l}\text { Weight (Kg.) } \\
\text { Total body water (liters) } \\
\text { Extracellular water (liters) } \\
\text { Intracellular water (liters) } \\
\text { Total body solids (Kg.) } \\
\text { Total body sodium (mEq.) } \\
\text { Plasma sodium concentration (mEq./L.) } \\
\text { Extracellular sodium (mEq.) } \\
\text { Non-extracellular sodium (mEq.) } \\
\text { Non-extracellular sodium concen. (mEq./L.) } \\
\text { Total body chloride (mEq.) } \\
\text { Plasma chloride concentration (mEq./L.) } \\
\text { Extracellular chloride (mEq.) } \\
\text { Non-extracellular chloride (mEq.) }\end{array}$ & $\begin{array}{r}52.7 \\
32.4 \\
10.2 \\
22.2 \\
20.3 \\
1,840 . \\
140 . \\
1,430 . \\
410 . \\
18 . \\
1,590 . \\
108 . \\
1,220 . \\
370 .\end{array}$ & $\begin{array}{r}51.0 \\
30.3 \\
10.4 \\
19.9 \\
20.7 \\
2,010 . \\
139 . \\
1,450 . \\
560 . \\
28 .\end{array}$ & $\begin{aligned} 50.9 \\
30.1 \\
11.5 \\
18.6 \\
20.8 \\
2,120 . \\
142 . \\
1,630 \\
490 . \\
26 . \\
1,870 . \\
102 . \\
1,300 \\
570\end{aligned}$ & $\begin{array}{c}48.7 \\
27.5 \\
10.3 \\
17.2 \\
21.2 \\
1,990 . \\
138 . \\
1,420 \\
570 . \\
33 .\end{array}$ \\
\hline
\end{tabular}

early transient extracellular shift of water and the later development of increased extracellular fluid volume account for the observed changes in body chioride.

\section{DISCUSSION}

The present studies of some aspects of the changes in body composition induced by corticotropin, as measured by dilution techniques, are in substantial agreement with the findings of Bartter and his co-workers (2) who applied metabolic balance methods to the same problem. The latter workers demonstrated the positive sodium and chloride balances which may occur and inferred that the sodium is retained in large measure as intracellular sodium. Our data corroborate this positive balance and demonstrate that non-extracellukar sodium and chloride may be greatly increased in some patients undergoing treatment.

The data relating to body solids and body water distribution indicate a variable response to the administration of corticotropin. W. C. and H. C. revealed a decrease in intracellular water volume which was maintained throughout the period of observation (despite the development of extracellular fluid retention in W. C. after twelve days of treatment). Each of these patients also demonstrated an increase in extracellular fluid volume at a time relatively early in treatment. Both patients showed progressive increase in total body solids during the course of therapy.

The body composition changes in $T$. T. and R. F. were in sharp contrast to the changes described in H. C. and W. C. The progressive in- crease in total body water in T. T. and R. F. reflected an increase in cell water. The extracellular fluid volume which had been initially decreased as a result of intracellular water shift was partially or completely restored at the time of the last measurement. An initial large decrease in total body solids occurred and continued for at least the first two weeks of treatment. This effect had been completely reversed in both patients at the time of the last measurement (43 and 34 days) when total solids were found to be greater than the control value.

These studies fail to demonstrate a single pattern of response to corticotropin. There probably are numerous biologic variables, known and unknown, which determine the clinical and metabolic pattern of response in a particular patient. The functional state of the adrenal cortex at the time corticotropin is administered may be one factor of significance in the observed variability of effects among individuals. Animal studies by Deane, Shaw and Greep (10) and Bacchus (11) have demonstrated by cytologic methods that an increase in the dietary sodium-potassium ratio produced evidence of decreased activity in the glomerular zone of the cortex, while lowering of the ratio produced changes indicative of increased activity in this area. Thus the previous level of sodium intake is probably one element influencing the effect of corticotropin. It has been suggested that androgenic hormone is derived from the reticular zone (12) and corticosteroids from the fascicular zone of the cortex (13). Such precise division may not be correct, but variables may 
exist which affect these areas of the cortex differentially, and which obviously cannot be properly controlled before they have been defined. The observation that the levels of dietary fat and carbohydrate may significantly modify the clinical and metabolic effects of corticotropin (14) is another indication that the intensity of the adrenocorticotropic stimulus is not the only determinant of the degree and nature of adrenal cortical activity. The nature and degree of illness as well as the impact of corticotropin therapy on the illness itself, in contrast to the effect of the hormone on water distribution, may also influence the response.

\section{SUMMARY}

1. Four patients with rheumatic diseases were treated with corticotropin for periods ranging between nineteen and forty-three days.

2. Two patients retained water intracellularly during the first week of treatment, and simultaneously showed a shift of extracellular water into the cells. The decrease in extracellular fluid volume was subsequently restored on further treatment. In two patients, intracellular water was decreased throughout therapy and a transient shift of cell water to the extracellular fluid was noted early in treatment. One of these patients developed a marked increase in extracellular fluid volume after two weeks of corticotropin.

3. Total body solids decreased and then rose in two patients, and increased progressively in two patients.

4. Sodium retention was induced in three patients as indicated by a rise in total body sodium. All or most of this retained sodium became part of the non-extracellular electrolyte.

5. In two of three patients, there was retention of chloride mainly as non-extracellular chloride. In the third patient, changes in total body chloride were consistent with changes in extracellular fluid volume.

6. Under the conditions of these studies, markedly different patterns of response to corticotropin have been observed.

\section{CASE SUM MARIES}

1. Rheumatoid spondylitis: T. T., a fifteen-year-old Chinese boy, had a history of rheumatoid arthritis since seven years of age. There had been three exacerbations of the disease during the intervening period. On admission to the hospital, he was afebrile. He appeared thin but well developed. The erythrocyte sedimentation rate was $94 \mathrm{~mm}$. per hour (Westergren method), but other routine laboratory tests and electrocardiogram were within normal limits. There was tenderness of the knees and ankles as well as limitation of hyperextension of the hips. X-rays revealed generalized changes of rheumatoid arthritis and ankylosing spondylitis. $\mathrm{He}$ was treated with corticotropin in a dosage of $100 \mathrm{mg}$. daily for eight weeks with lessening of joint pain and inflammation but no decrease in deformities. In response to corticotropin therapy, the erythrocyte sedimentation rate fell gradually to $9 \mathrm{~mm}$. per hour in 45 days. Two eosinophile counts were 65 and 38 per $\mathrm{mm}^{2}$., respectively, before treatment; during treatment numerous counts ranged between 12 and 37 per $\mathrm{mm}^{2}$.

2. Rheumatic fever: R. F., a fourteen-year-old white boy, was admitted to the hospital with a history of fever and polyarthritis of two weeks' duration. The temperature was $103.4^{\circ} \mathrm{F}$. on admission. He was moderately well nourished and well developed. There was no evidence of carditis on physical examination. The knees, ankles, and feet were swollen and tender. Erythrocyte sedimentation rate was $92 \mathrm{~mm}$. per hour, C-reactive protein $4+$ and antistreptolysin titer 300 and 500 . X-ray of the chest was within normal limits. Aspirin therapy, which was continued for one month, produced an immediate fall in temperature and erythrocyte sedimentation rate with relief of symptoms. Following withdrawal of aspirin, however, there was an exacerbation of symptoms. An early aortic diastolic murmur was heard for the first time. Corticotropin was then administered in a dosage of 100 mg. daily for $\mathbf{5 0}$ days. There was no further polyarthritis or fever, and the erythrocyte sedimentation rate fell from 60 to $20 \mathrm{~mm}$. per hour in the first 3 weeks. The eosinophile count fell from 100 to 42 per $\mathrm{mm}^{2}$. on the second day. When corticotropin treatment was halted after $\mathbf{5 0}$ days, there was no relapse. The aortic diastolic murmur was not heard after 31 days of corticotropin and did not reappear when corticotropin was discontinued. $\mathrm{X}$-rays of the chest showed the heart to be of normal size and shape at the time of discharge.

3. Rheumatic fever: H. C., a seventeen-year-old white girl, had previous episodes of rheumatic fever at six and nine. Two months prior to admission, the patient developed migratory arthralgias and continued low grade fever. There were no symptoms of diminished cardiac reserve. On admission, the temperature was $100.4^{\circ} \mathrm{F}$. and pulse 120 per minute. Blood pressure was $120 / 95 \mathrm{~mm}$. $\mathrm{Hg}$. The heart was not enlarged, but a diastolic rumbling murmur was heard at the apex. Except for slight warmth in the knees, there were no other findings of significance on physical examination. Routine laboratory tests and electrocardiogram were within normal limits. Erythrocyte sedimentation rate was $9 \mathrm{~mm}$. per hour. Corticotropin was injected in a dosage of $100 \mathrm{mg}$. daily. The sedimentation rate remained within normal limits and the eosinophile count fell from 87 to 9 per $\mathrm{mm}^{2}$. After 28 
days of treatment the patient had a psychotic episode and corticotropin was discontinued two days later. There was no evidence of diminished cardiac reserve during the period of treatment.

4. Rheumatoid arthritis: W. C., a forty-two-year-old, normotensive, white woman, had a history of increasing pain and stiffness in numerous joints over a period of 13 years. She was afebrile on admission and during the pretreatment period. Significant findings on physical examination were confined to the joints. There was slight to moderate restriction of movement of the shoulders, ankles, elbows, and wrists and small joints of the hand with moderate pain on passive motion. Routine laboratory tests and electrocardiogram were normal. The erythrocyte sedimentation rate ranged between 33 and 45 mm. before corticotropin treatment. Corticotropin was administered in a dosage of $100 \mathrm{mg}$. daily. This resulted in relief of joint pain and decrease in stiffness. The sedimentation rate fell to $25 \mathrm{~mm}$. per hour in eight days and the eosinophile count from 87 to 7 per $\mathrm{mm}^{2}$. The patient gained $5.2 \mathrm{Kg}$. between the twelfth and nineteenth day of therapy. She became dyspneic and orthopneic. Rales were heard at both bases and there was an increase in heart size and hilar congestion on $\mathrm{X}$-ray. Venous pressure rose to $200 \mathrm{~mm}$. of saline. Following discontinuation of corticotropin therapy, there was a large diuresis with loss of edema and $9.1 \mathrm{Kg}$. of weight in two days. The lungs cleared and dyspnea disappeared. There was no relapse of the arthritis during the following eightmonth period.

\section{REFERENCES}

1. Sprague, R. G., Power, M. H., Mason, H. L., Albert, A., Mathieson, D. R., Hench, P. S. Kendall, E. C., Slocumb, C. H., and Polley, H. F., Observations on the physiologic effects of cortisone and ACTH in man. Arch. Int. Med., 1950, 85, 199.

2. Bartter, F. C., Fourman, P., Albright, F., Forbes, A. P., Jeffries, W. McK., Griswold, G., Dempsey, E., Bryant, D., and Carroll, E., The effect of adrenocorticotropic hormone in panhypopituitarism. J. Clin. Invest., 1950, 29, 950.
3. Levitt, M. F., and Bader, M. E., Effect of cortisone and ACTH on fluid and electrolyte distribution in man. Am. J. Med., 1951, 11, 715.

4. Ziff, M., Simson, J., and Bunim, J. J., Effect of ACTH on water distribution in man as measured by antipyrine, T 1824 and bromide. J. Clin. Invest., 1952, 31, 829.

5. Deane, N., II. Methods of study of body water compartments (space techniques). Methods in Medical Research, Chicago, Year Book Publishers, 1952, 5, 159.

6. Soberman, R., Brodie, B. B., Levy, B. B., Axelrod, J., Hollander, V., and Steele, J. M., The use of antipyrine in the measurement of total body water in man. J. Biol. Chem., 1949, 179, 31.

7. Deane, N., and Smith, H. W., The distribution of sodium and potassium in man. J. Clin. Invest., 1952, 31, 197.

8. Deane, N., Ziff, M., and Smith, H. W., The distribution of total body chloride in man. J. Clin. Invest. 1952, 31, 200.

9. Brodie, B. B., Brand, E., and Leshin, S., The use of bromide as a measure of extracellular fluid. J. Biol. Chem., 1939, 130, 555.

10. Deane, H. W., Shaw, J. H., and Greep, R. O., The effect of altered sodium or potassium intake on the width and cytochemistry of the zona glomerulosa of the rat's adrenal cortex. Endocrinology, 1948, 43, 133.

11. Bacchus, H., Cytochemical study of the adrenal cortex of the rat under salt stresses. Am. J. Physiol., 1950, 163, 326.

12. Blackman, S. S., Concerning the function and origin of the reticular zone of the adrenal cortex. Bull. Johns Hopkins Hosp., 1946, 78, 180.

13. Forbes, A. P., and Albright, F., A comparison of the 17-ketosteroid excretion in Cushing's syndrome associated with adrenal tumor and with adrenal hyperplasia. J. Clin. Endocrinol., 1951, 11, 926.

14. Kinsell, L. W:, Olson, F., Boling, L., Partridge J., and Margen, S., Modification of the clinical and metabolic effects of ACTH by dietary means. J. Clin. Endocrinol., 1951, 11, 1030. 